\title{
Influence of Synthesis Parameters on Luminescence of Thenoyltrifluoroacetone Europium Powders
}

\author{
Dulce Y. Medina-Velazquez, Manuel Barraza, Miguel Barron, Isaias Hileio, Victor Colin \\ División de Ciencias Básicas e Ingeniería, Universidad Autónoma Metropolitana-Azcapotzalco, Reynosa, Mexico \\ Email:bmma@correo.azc.uam.mx
}

How to cite this paper: Medina-Velazquez, D.Y., Barraza, M., Barron, M., Hileio, I. and Colin, V. (2018) Influence of Synthesis Parameters on Luminescence of Thenoyltrifluoroacetone Europium Powders. Journal ot Materials Science and Chemical Engineering, 6, 1-8.

https://doi.org/10.4236/msce.2018.68001

Received: June 26, 2018

Accepted: August 3, 2018

Published: August 6, 2018

Copyright $\odot 2018$ by authors and Scientific Research Publishing Inc. This work is licensed under the Creative Commons Attribution International License (CC BY 4.0).

http://creativecommons.org/licenses/by/4.0/

\begin{abstract}
In the last years the development of new luminescent materials was grow highly in order to find efficient materials with low cost of processing. In this way the organic luminescent materials have special attention because its special characteristics, like antenna effect, low temperature processing, possibility to make translation to polymeric and flexible compounds. In this work luminescent powders of TTA:Eu ${ }^{3+}$ by sol-gel method were synthesized in order to define the synthesis parameters of the highest luminescence. The temperatures of heat treatment were $80^{\circ} \mathrm{C}, 100^{\circ} \mathrm{C}, 200^{\circ} \mathrm{C}$ and the concentration of Europium where $10 \%, 20 \%, 30 \%$ and $40 \%$ mol (TTA-10Eu, TTA-20Eu, TTA-30Eu, and TTA-40Eu). Fourier Transform Infrared Rays analysis (FTIR) and emission luminescence measures, the best conditions of synthesis were obtained at $40 \% \mathrm{~mol}$ of Europium and $80^{\circ} \mathrm{C}$ of heat treatment, at $272 \mathrm{~nm}$ of excitation. All the samples present the corresponded $\mathrm{Eu}^{3+}$ ion transitions the ${ }^{5} \mathrm{D}_{0} \rightarrow{ }^{7} \mathrm{~F}_{\mathrm{J}}(\mathrm{J}=0,1$, and 2$)$. This confirms the great possibilities of these materials for optoelectronic applications.
\end{abstract}

\section{Keywords}

Luminescence, Europium, Organic Compounds, Thenoyltrifluoroacetone, Antenna Effect

\section{Introduction}

The photophysical properties of trivalent lanthanide ions $\left(\operatorname{Ln}^{3+}\right)$ make them of great interest to the researchers in the luminescence field. $\mathrm{Ln}^{3+}$ ions, have narrow emission bands that arise from intraconfigurational transitions [1].

The trivalent europium ion $\left(\mathrm{Eu}^{3+}\right)$ specifically has a narrow emission band that provides highly pure red color emission and also has a considerably long 
lifetime which makes it very useful in applications in display devices [2] [3] [4] as well as in medical diagnosis [5] [6] [7] [8].

Nevertheless, the absorption and emission are considered weak for both of this applications and in order to develop both of this weak points, $\mathrm{Eu}^{3+}$ requires some indirect excitation, making us of ligands and the antenna effect, a mechanism in which the ligand absorbs energy and then transfers it to the central atom, ion or molecule. This results in higher energy absorption and also a higher emission [9].

Inorganic ligands are commonly used, but more recently the efforts have turned to the study of organic ligands. $\beta$-Diketonate ligands are among the most largely investigated ligands [10] [11] [12]. Previous works have shown that $\beta$-diketonate complexes such as thenoyltrifluoroacetonate (TTA) are very efficient antennae for the trivalent europium ion $\left(\mathrm{Eu}^{3+}\right)$ [13] [14]. In this work we try to find the best synthesis conditions for the $\mathrm{Eu}^{3+}$ ion with TTA as a ligand $\left(\mathrm{Eu}(\mathrm{TTA})_{3}\right)$.

\section{Experimental Procedure}

\subsection{Synthesis of Powders}

The chemicals used for the synthesis of TTA:Eu ${ }^{3+}$ was Thenoyltrifluoroacetone $\left(\mathrm{C}_{8} \mathrm{H}_{5} \mathrm{~F}_{3} \mathrm{O}_{2} \mathrm{~S}\right.$, 99.99\%); Europium (III) nitrate pentahydrate $\left(\mathrm{EuNO}_{3}\right)_{3} \cdot 5 \mathrm{H}_{2} \mathrm{O}$, 99.99\%), Sodium Bicarbonate $\left(\mathrm{NaHCO}_{3}, 99.99 \%\right)$; all of them were purchased from Sigma Aldrich. Besides, distilled water and ethanol were used as solvent and used without further purification. In a typical synthesis $15.5 \mathrm{mmol}$ of Thenoyltrifluoroacetone was dissolved into $15 \mathrm{~mL}$ of ethanol and kept under vigorous stirring at room temperature for 30 minutes. In another biker, europium nitrate was dissolved in $10 \mathrm{~mL}$ of deionized water and from this solution an appropriate volume was dropped to the Thenoyltrifluoroacetone solution to fix the europium composition at $10 \%, 20 \%, 30 \%$ and $40 \%$ mol. The $\mathrm{NaHCO}_{3}$ was added to the solution with the aim to adjust the $\mathrm{pH}$ at 7 . Finally, the solution was dried at $100^{\circ} \mathrm{C}$ for $24 \mathrm{~h}$. and a white powder was obtained.

\subsection{Characterization of Powders}

The powders were characterized by XRD in reflective mode on a Bruker Eco D8 ADVANCE diffractometer with Ni-filtered $\mathrm{Cu}$ Kal radiation $(\lambda=0.15406 \mathrm{~nm})$ and FTIR using a Perkin Elmer 2000 model. For sample preparation, it was used the $\mathrm{KBr}$ pellet technique. For the measurements, the spectra were recorded from 4000 to $400 \mathrm{~cm}^{-1}$. Photoluminescence spectra were recorded by means of a Horiba Jobin-Yvon Fluorolog spectrofluorometer equipped with a $150 \mathrm{~W}$ ozone-free Xe lamp for the steady state mode. All the measurements were carried out at room temperature.

\section{Results and Discussion}

The XRD analysis for the powders obtained at different temperatures for a con- 
centration of $40 \% \mathrm{~mol}$ is shown in Figure 1, as it shown, an amorphous phase was observed for all temperatures process, with a crystal size in order of nanometers, when the temperature was increased the peaks position change that a possible consequence of change of phase.

The FTIR analysis for the powders obtained at a temperature of $80^{\circ} \mathrm{C}$ is shown in Figure 2, as it shown, the corresponded bonds of hydroxyl groups $(\mathrm{OH})$, appears at $3300-2900 \mathrm{~cm}^{-1}$, the presence of carbonyl group $\mathrm{C}=\mathrm{O}$ is confirmed at $1691 \mathrm{~cm}^{-1}$ and $1632 \mathrm{~cm}^{-1}$. The $\mathrm{C}=\mathrm{C}$ bond was observed at $1542 \mathrm{~cm}^{-1}$ and finally the vibration of $\mathrm{C}_{-} \mathrm{CF}_{3}$ was appeared at $1130 \mathrm{~cm}^{-1}$ and $1295 \mathrm{~cm}^{-1}$

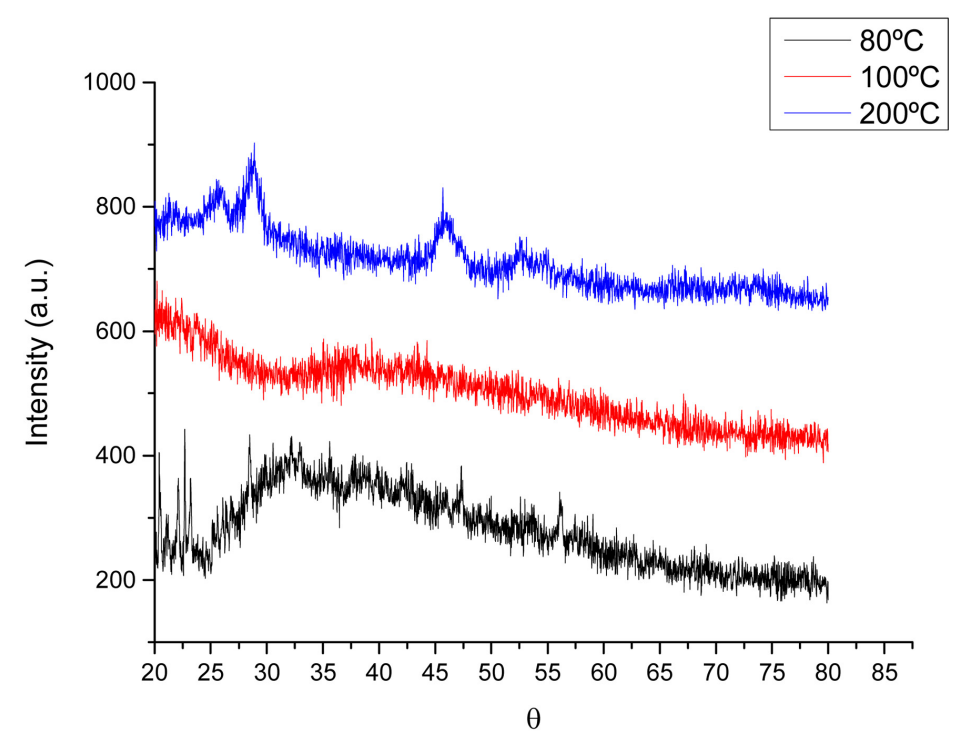

Figure 1. XRD spectra of powders of TTA: $\mathrm{Eu}^{3+}$ obtained at $80^{\circ} \mathrm{C}, 100^{\circ} \mathrm{C}$ and $200^{\circ} \mathrm{C}$ for TTA-40Eu samples.

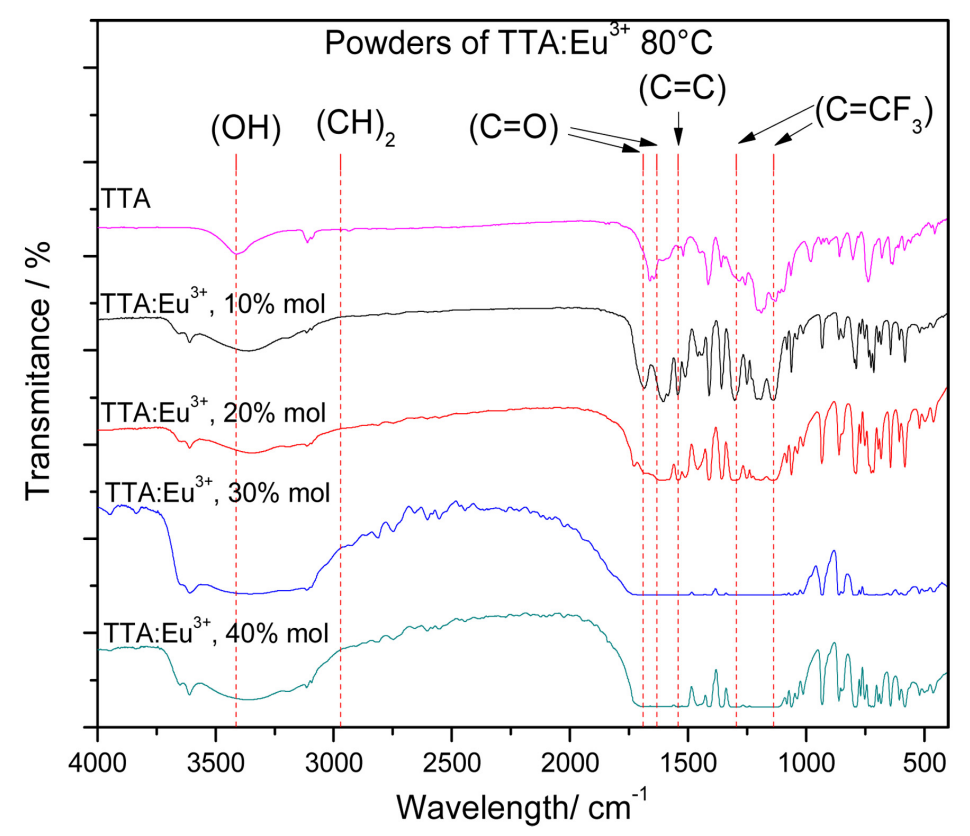

Figure 2. FTIR spectra of powders of TTA: $\mathrm{Eu}^{3+}$ obtained at $80^{\circ} \mathrm{C}$. 
which confirm the adequate formation of TTA: $\mathrm{Eu}^{3+}$ powders.

Figure 3 showed the corresponded FTIR spectra of the powders obtained at $100^{\circ} \mathrm{C}$ and $200^{\circ} \mathrm{C}$, as it shown, the spectra doesn't have significant changes with the temperature, it's means that the increment on the synthesis temperature, doesn't change the structure of the powders, which confirm that the corresponded bonds of TTA: $\mathrm{Eu}^{3+}$ is obtained at the all temperatures.

Figure 4 showed the emission intensity of luminescent powders obtained at $80^{\circ} \mathrm{C}$ for an excitation wavelength of a) $272 \mathrm{~nm}$ and b) $370 \mathrm{~nm}$. As it shows the corresponded $\mathrm{Eu}^{3+}$ ion ${ }^{5} \mathrm{D}_{0} \rightarrow{ }^{7} \mathrm{~F}_{\mathrm{J}}(\mathrm{J}=0,1$, and 2$)$ is observed for all the concentration used, but the highest intensity is observed for the sample TTA-40Eu, in other hand the emission at $616 \mathrm{~nm}$ was tested for the excitation wavelength of 272 and $370 \mathrm{~nm}$, as Figure 4 shown the highest intensity was founded at $370 \mathrm{~nm}$ as is shown in incise c).
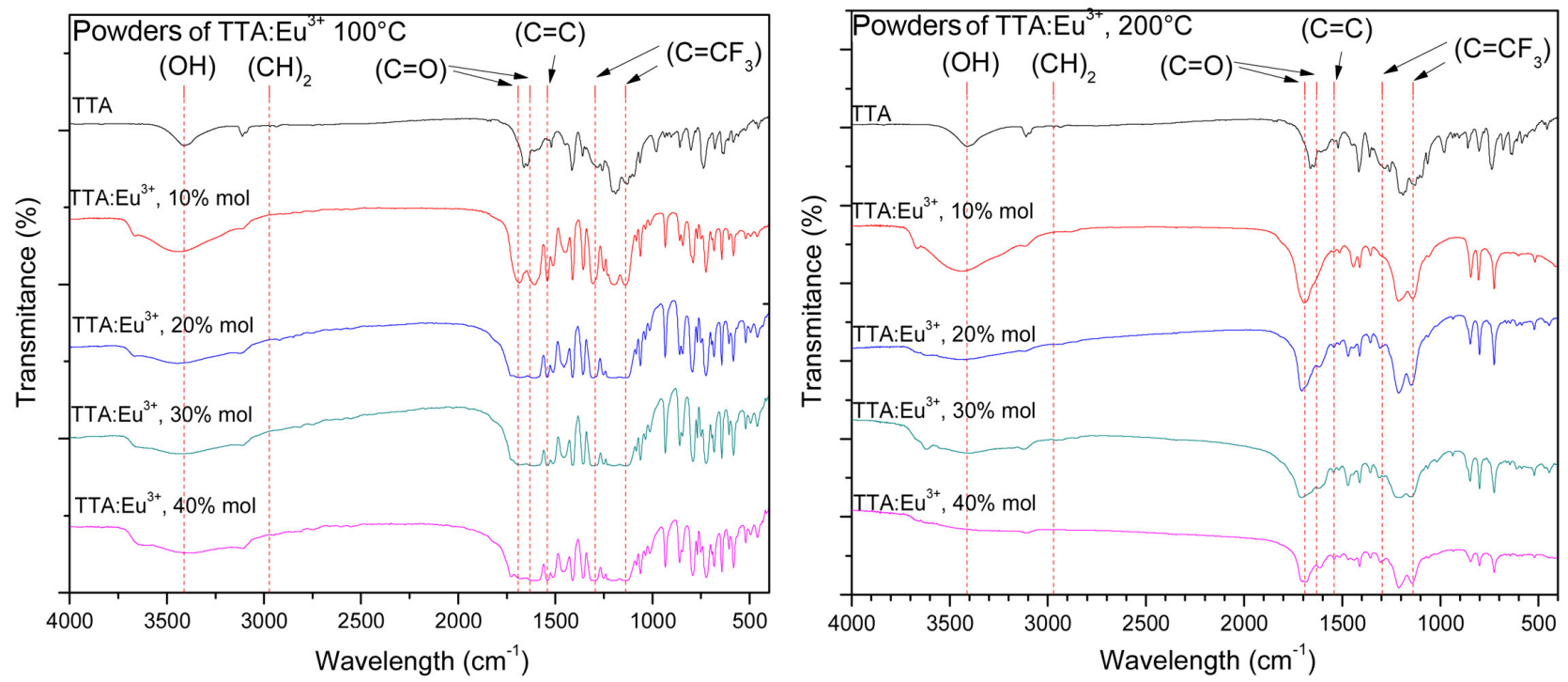

Figure 3. FTIR spectra of powders of TTA:Eu ${ }^{3+}$ obtained at $100^{\circ} \mathrm{C}$ and $200^{\circ} \mathrm{C}$.

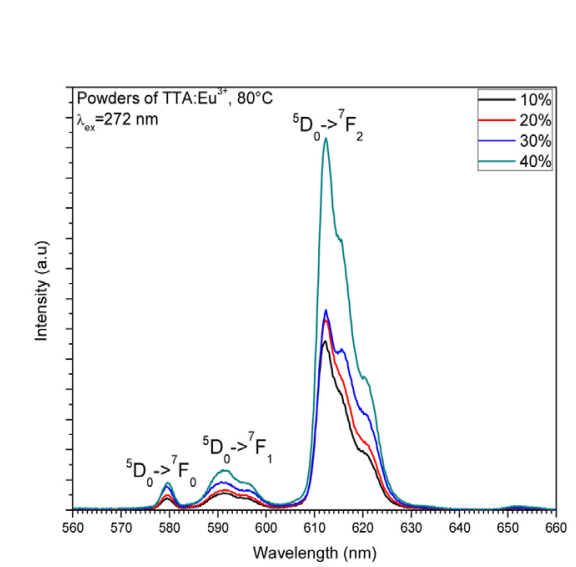

(a)

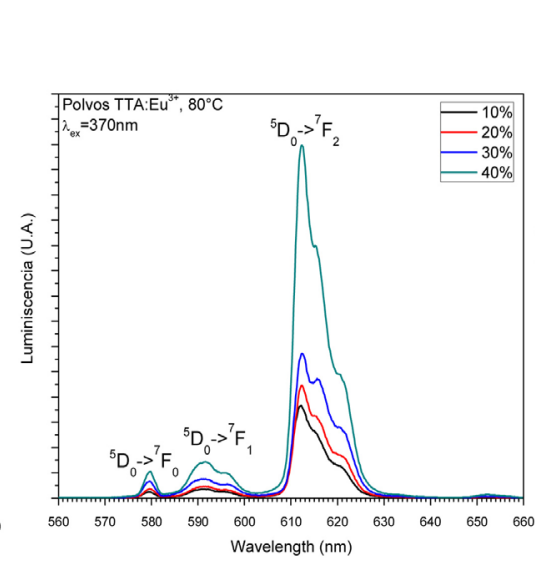

(b)

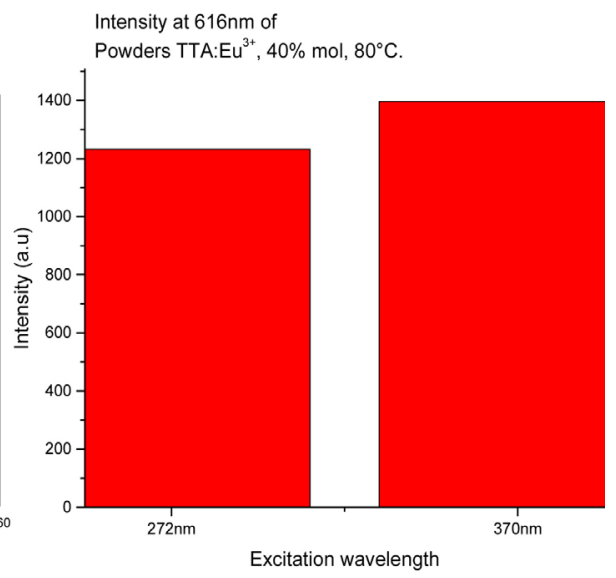

(c)

Figure 4. Emission spectra of TTA:Eu ${ }^{3+}$ powders obtained at $80^{\circ} \mathrm{C}$, for (a) $272 \mathrm{~nm}$ (b) $370 \mathrm{~nm}$ of excitation and (c) comparison of intensity of $616 \mathrm{~nm}$ of $272 \mathrm{~nm}$ and $370 \mathrm{~nm}$ excitation. 
Figure 5 showed the emission intensity of luminescent powders obtained at $100^{\circ} \mathrm{C}$ for an excitation wavelength of a) $272 \mathrm{~nm}$ and b) $370 \mathrm{~nm}$ and in c) the intensity at $616 \mathrm{~nm}$, for both excitation wavelengths. As it shows the intensity of emission decrease with the concentration of europium, in contrast with the powders obtained at $80^{\circ} \mathrm{C}$ the highest intensity was observed for the TTA-10Eu sample. In other hand the highest emission in contrast with the temperature of $80^{\circ} \mathrm{C}$ was obtained at $272 \mathrm{~nm}$.

Finally Figure 6 showed the emission intensity of luminescent powders obtained at $200^{\circ} \mathrm{C}$ for an excitation wavelength of a) $272 \mathrm{~nm}$ and b) $370 \mathrm{~nm}$ and in c) the intensity at $616 \mathrm{~nm}$, for both excitation wavelengths. As it shown, the intensity of emission is very small for all samples, but at $272 \mathrm{~nm}$ of excitation wavelength the highest emission was obtained for the TTA-20Eu sample, and at $370 \mathrm{~nm}$ of excitation wavelength the highest emission was obtained for the TTA-10Eu sample. In c) is showed the emission intensity of both emissions in order to show that the highest emission was obtained for the sample of TTA-10Eu excited at $272 \mathrm{~nm}$.

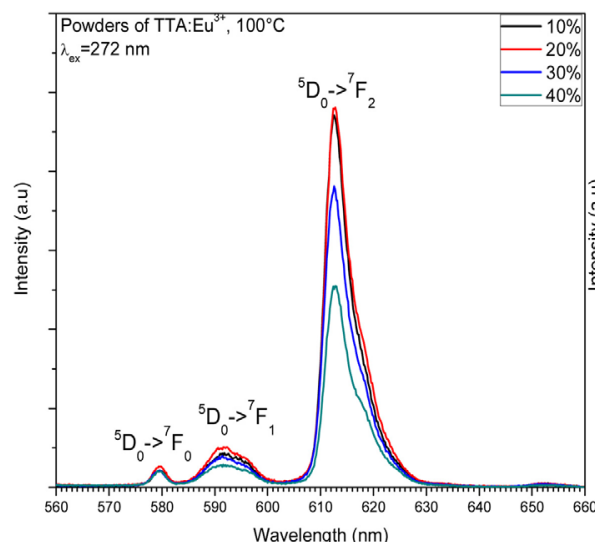

(a)

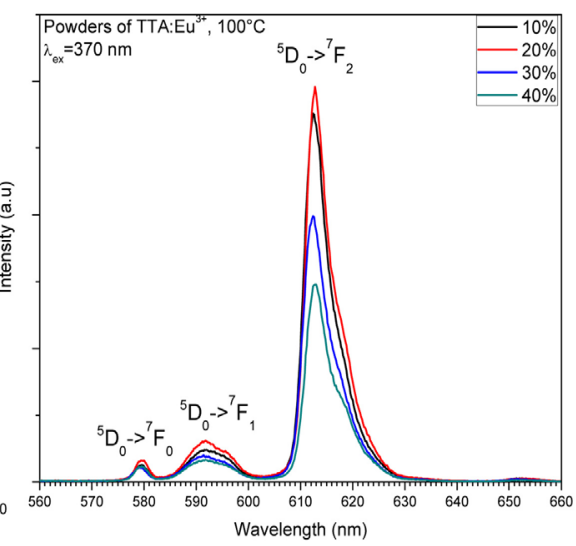

(b)

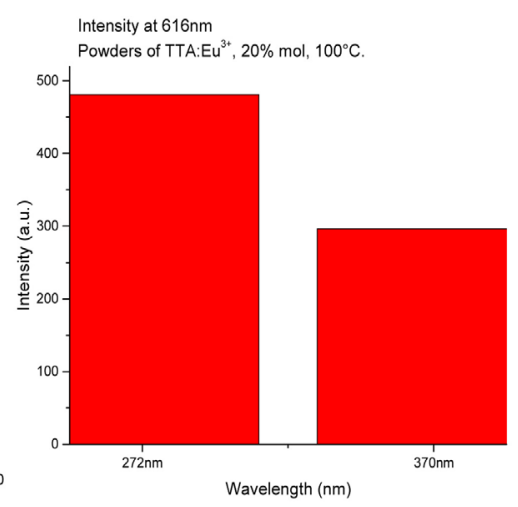

(c)

Figure 5. Emission spectra of TTA:Eu ${ }^{3+}$ powders obtained at $100^{\circ} \mathrm{C}$, for (a) $272 \mathrm{~nm}$ (b) $370 \mathrm{~nm}$ of excitation and (c) comparison of intensity of $616 \mathrm{~nm}$ of $272 \mathrm{~nm}$ and $370 \mathrm{~nm}$ excitation.

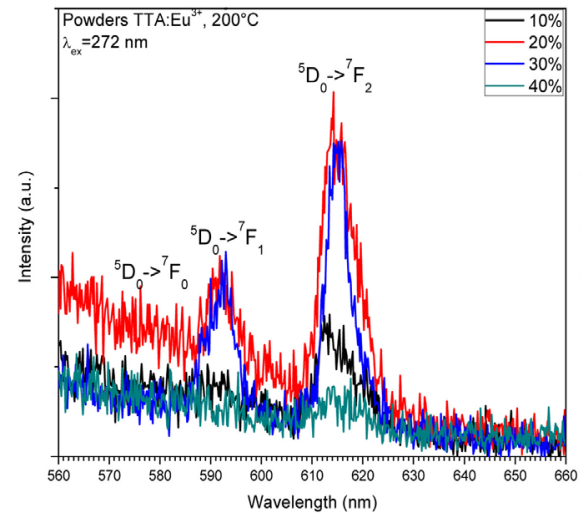

(a)

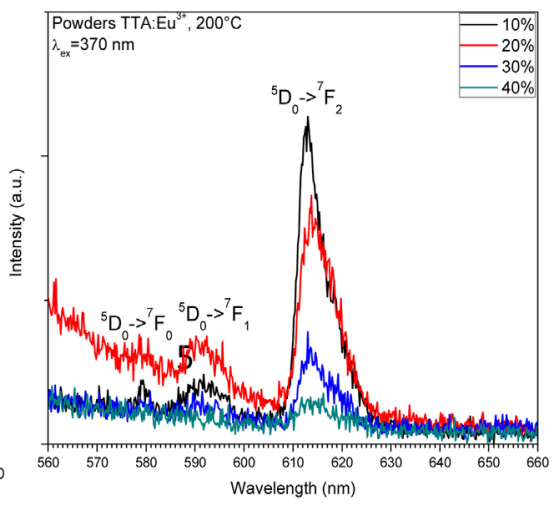

(b)

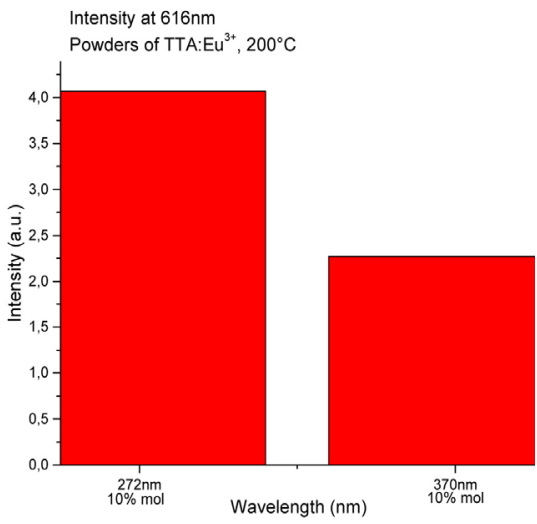

(c)

Figure 6. Emission spectra of TTA:Eu ${ }^{3+}$ powders obtained at $200^{\circ} \mathrm{C}$, for (a) $272 \mathrm{~nm}$ (b) $370 \mathrm{~nm}$ of excitation and (c) comparison of intensity of $616 \mathrm{~nm}$ of $272 \mathrm{~nm}$ and $370 \mathrm{~nm}$ excitation. 
Figure 7 is a resume of the intensity emission of samples at $616 \mathrm{~nm}$ wavelength, and it showed a comparative columns which shows the maximum emission intensity obtained for each temperature at different excitation wavelengths. It's confirm that the emission intensity decrease with an increment in the temperature of heat treatment, nerveless the highest emission for the samples obtained at $100^{\circ} \mathrm{C}$ and $200^{\circ} \mathrm{C}$ of temperature is obtained at $272 \mathrm{~nm}$ of excitation wavelength.

\section{Conclusion}

The synthesis parameters as temperature, europium concentration and excitation wavelength were studied in order to find the highest luminescence. The results showed the corresponded $\mathrm{Eu}^{3+}$ transitions of all the samples ${ }^{5} \mathrm{D}_{0} \rightarrow{ }^{7} \mathrm{~F}_{\mathrm{J}}(\mathrm{J}=0,1$, and 2). The $\mathrm{Eu}^{3+}$ concentration played an important role in the optical properties, as it shown the intensity of emission increase with the $\mathrm{Eu}^{3+}$ concentration for the $80^{\circ} \mathrm{C}$ temperature of heat treatment. When the temperature is increased, this condition was inverted, obtaining the highest intensity at small $\mathrm{Eu}^{3+}$ concentrations. By FTIR the corresponded bonds of thenoyltrifluoroacetonate were observed $\left(\mathrm{O}-\mathrm{H}, \mathrm{CH}_{2}\right.$, $\mathrm{C}=\mathrm{O}, \mathrm{C}=\mathrm{C}, \mathrm{C}-\mathrm{CF}_{3}$ ) that confirm the adequate synthesis of TTA:Eu ${ }^{3+}$ for all samples. Finally the excitation wavelengths of $272 \mathrm{~nm}$ and $370 \mathrm{~nm}$ were studied for all temperatures and concentration. The results showed that the highest intensity was obtained for the sample TTA-40Eu synthesized at $80^{\circ} \mathrm{C}$ and excited at $370 \mathrm{~nm}$; for the temperatures of $100^{\circ} \mathrm{C}$ and $200^{\circ} \mathrm{C}$, the highest intensity was obtained at 272 $\mathrm{nm}$ of excitation wavelength and $20 \% \mathrm{~mol}$ of Europium ion.

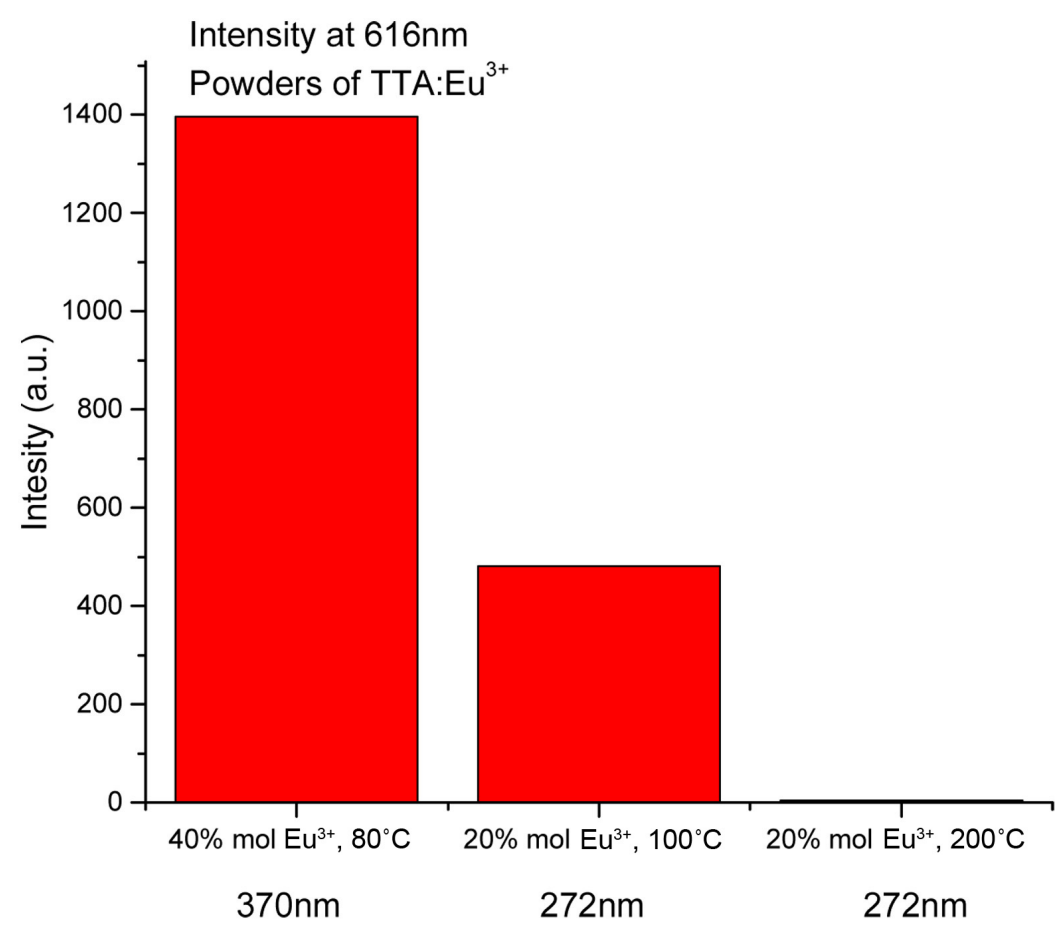

Figure 7. Comparison of intensity emission at $616 \mathrm{~nm}$ of $272 \mathrm{~nm}$ and $370 \mathrm{~nm}$ excitation for the powders obtained at $80^{\circ} \mathrm{C}, 100^{\circ} \mathrm{C}$ and $200^{\circ} \mathrm{C}$. 


\section{Acknowledgements}

This work was supported by CONACyT project 254280. The authors wish to acknowledge the technical assistance of, Ms. T Maribel Pacheco Ramos and Dr. Veronica Melo Mendoza.

\section{Conflicts of Interest}

The authors declare no conflicts of interest regarding the publication of this paper.

\section{References}

[1] Bünzli, J.-C.G. and Choppin, G.R. (1989) Lanthanide Probes in Life, Chemical and Earth Sciences: Theory and Practice. Elsevier, Amsterdam.

[2] Justel, T., Nikol, H. and Ronda, C. (1998) Neue Entwicklungen auf dem Gebiet lumineszierender Materialien für Beleuchtungs- und Displayanwendungen. Angewandte Chemie, 110, 3250-3271.

https://doi.org/10.1002/(SICI)1521-3757(19981116)110:22<3250::AID-ANGE3250> 3.0.CO;2-1

[3] Kido, J. and Okamoto, Y. (2002) Organo Lanthanide Metal Complexes for Electroluminescent Materials. Chemical Reviews, 102, 2357-2368. https://doi.org/10.1021/cr010448y

[4] Wang, H., He, P., Liu, S., Shi, J. and Gong, M. (2010) New Multinuclear Europium (III) Complexes as Phosphors Applied in Fabrication of Near UV-Based Light-Emitting Diodes. Inorganic Chemistry Communications, 13, 145-148. https://doi.org/10.1016/j.inoche.2009.10.031

[5] Richardson, F.R. (1982) Terbium (III) and Europium (III) Ions as Luminescent Probes and Stains for Biomolecular Systems. Chemical Reviews, 82, 541-552. https://doi.org/10.1021/cr00051a004

[6] Hammila, I. (1995) Luminescent Lanthanide Chelates-A Way to Diagnostic Methods. Journal of Alloys and Compounds, 225, 480-485. https://doi.org/10.1016/0925-8388(94)07069-5

[7] Yuan, J., Matsumoto, K. and Kimura, H. (1998) A New Tetradentate $\beta$-DiketonateEuropium Chelate That Can Be Covalently Bound to Proteins for Time-Resolved Fluoroimmunoassay. Analytical Chemistry, 70, 596-601. https://doi.org/10.1021/ac970936z

[8] Hemmilä, I., Stahlberg, T. and Mottran, P. (1994) Bioanalytical Applications of Labeling Technologies Immunoassays, Wallac, Turku.

[9] Benavente, E.C. (2006) Propiedades Ópticas De Complejos Lantánidos De Eu3 ${ }^{+}$Y $\mathrm{Tb}^{+}$Intercalados En Arcillas Naturales. SAM CONAMET, Santiago.

[10] Sata, S. and Wada, M. (1970) Relations between Intramolecular Energy Transfer Efficiencies and Triplet State Energies in Rare Earth $\beta$-Diketone Chelates. Bulletin of the Chemical Society of Japan, 43, 1955. https://doi.org/10.1246/bcsj.43.1955

[11] Sager, W.F., Filipescu, N. and Serafin, F.A. (1964) Substituent Effects on Intramolecular Energy Transfer. I. Absorption and Phosphorescence Spectra of Rare Earth $\beta$-Diketone Chelates. The Journal of Physical Chemistry, 64, 1092.

[12] Filipescu, N., Sager, W.F. and Serafin, F.A. (1964) Substituent Effects on Intramolecular Energy Transfer. II. Fluorescence Spectra of Europium and Terbium 
$\beta$-Diketone Chelates. The Journal of Physical Chemistry, 68, 3324-3346. https://doi.org/10.1021/j100793a039

[13] Yuan, J., Sueda, S., Somazawa, R., Matsumoto, K.E. and Matsumoto, K.A. (2003) Structure and Luminescence Properties of the Tetradentate $\beta$-Diketonate-Europium (III) Complexes. Chemistry Letters, 32, 492. https://doi.org/10.1246/cl.2003.492

[14] Steemers, F.J., Verboom, W., Reinhoudt, D.N., Vandertol, E.B. and Verhoven, J.W. (1995) New Sensitizer-Modified Calix [4] Arenes Enabling Near-UV Excitation of Complexed Luminescent Lanthanide Ions. Journal of the American Chemical Society, 117, 9408-9414. https://doi.org/10.1021/ja00142a004 